The Health, School, and Social Outcomes of Off-Reserve First Nations Children of Teenage Mothers

\author{
Anne Guèvremont \\ Health Analysis Division, Statistics Canada \\ Dafna Kohen \\ Health Analysis Division, Statistics Canada
}

aboriginal policy studies Vol. 3, no. 1\&2, 2014, pp. 29-53

This article can be found at:

http://ejournals.library.ualberta.ca/index.php/aps/article/view/18813

ISSN: $1923-3299$

Article DOI: http://dx.doi.org/10.5663/aps.v3i1-2.18813

aboriginal policy studies is an online, peer-reviewed and multidisciplinary journal that publishes original, scholarly, and policy-relevant research on issues relevant to Métis, non-status Indians and urban Aboriginal people in Canada. For more information, please contact us at apsjournal@ualberta.ca or visit our website at www.ualberta.ca/nativestudies/aps/. 


\title{
The Health, School, and Social Outcomes of Off-Reserve First Nations Children of Teenage Mothers
}

\author{
Anne Guèvremont \\ Health Analysis Division, Statistics Canada \\ Dafna Kohen ${ }^{1}$ \\ Health Analysis Division, Statistics Canada
}

\begin{abstract}
Children of teenage mothers differ in their health, social, and educational outcomes compared to children of older mothers. Even though the teen birth rate for First Nations women in Canada is higher than the national teen birth rate, there has been little research examining the outcomes of off-reserve First Nations children born to mothers who began childbearing in their teen years. Using data from the 2006 Aboriginal Peoples Survey, this study examined the health, social, and educational outcomes of off-reserve First Nations children, aged six to fourteen, who were born to teenage mothers, as compared to those born to older mothers. Offreserve First Nations children of teenage mothers were more likely to be rated by their mothers as having dental problems, more likely to have failed a grade, less likely to be rated as doing very well in school, and less likely to have maternal reports of school satisfaction. They were also more likely to be rated as not getting along well in the last six months with their teachers, parents, and siblings. Although some of these differences were explained by socio-economic characteristics (getting along with teachers and parents, doing well in school), differences in all three domains (dental problems, getting along with parents, grade failure and parental school satisfaction) remained. Recommendations for future research are discussed.
\end{abstract}

The teen birth rate for First Nations women in Canada is higher than the national teen birth rate. In 2004, one teenage First Nations woman in ten had a child, compared to one in fifty for all Canadian teenage women (Guimond and Robitaille 2008). Higher rates of teen motherhood for First Nations, as compared to non-Aboriginal women, are supported by the 2006 Aboriginal Children's Survey (Zukewich and O'Donnell 2008). The survey showed that 27 percent of those First Nations children not living on a reserve, and who were under the age of six, had mothers between the ages of fifteen and twenty-four, as compared to 8 percent of non-Aboriginal children. Research into Canadian, American, and Australian populations has found that children of teen mothers have poorer health and worse educational and social outcomes compared to children of non-teen mothers; however, little research thus far has used population-based data to examine the outcomes for Aboriginal children of teen mothers (see Guèvremont and Kohen [2013 a, b], for

1 Corresponding author: Dr. Dafna Kohen, Health Analysis Division, Statistics Canada, R.H. Coates Building, 24th floor, Ottawa, ON K1A 0T6 (t) 613-951-3346 (e) dafna.kohen@statcan.gc.ca.

aboriginal policy studies, vol. 3, no. 1\&2, 2014 
studies focusing on preschoolers' outcomes). This study will examine the health, social, and educational outcomes for six- to fourteen-year-old off-reserve First Nations children of teen mothers.

Guèvremont and Kohen (2013a) analyzed data from the 2006 Aboriginal Children's Survey and showed that, for two- to five-year-old off-reserve First Nations children of teen mothers, there were few differences in physical health outcomes between them and the children of older mothers, although children of teen mothers were more likely to have had dental problems. However, there were differences for all the child mental health outcomes examined.Specifically, off-reserve First Nations children of teenage mothers had lower scores of pro-social behaviours (e.g., sharing, helping) and higher scores of emotional symptoms (e.g., worrying, fearfulness), inattention-hyperactivity (e.g., being easily distracted), and conduct problems (e.g., fighting, losing their temper) when compared to off-reserve First Nations children of older mothers. Guèvremont and Kohen also found, as have others (Garner, Guimond, and Senécal, forthcoming), that off-reserve First Nations children of teenage mothers differed in their socio-economic circumstances when compared to offreserve First Nations children of older mothers; their mothers were more likely to have lower levels of education and the children to have a higher likelihood of living in a low-income or lone-parent family. Moreover, the higher levels of pro-social and emotional problems for children of teen mothers, as compared to children of older mothers, were found to be attributable to socio-economic factors, rather than to differences in child-bearing age. Yet differences in child inattention-hyperactivity and conduct problems persisted, and were not explainable by differences in socio-economic factors between teen and older mothers. These differences are important, as inattention-hyperactivity and conduct problems may be determinants of later school achievement and literacy skills, as well as social functioning (Alexander, Farhat, and Dauber 1993; McLelland, Morrison, and Homes 2010). To our knowledge, no studies have examined the relationship between having a teen mother and outcomes later in childhood for off-reserve First Nations children.

Research with the overall population has found that school-aged children of teenaged mothers are more likely to have poorer health, poorer educational outcomes, and worse social outcomes. Several studies have examined the health status of school-aged children of teenage mothers, with most finding that children of teenage mothers experience worse health than children of older mothers, even after accounting for differences in socio-economic status. For example, children of teen mothers were more likely to be rated as being in fair/ poor health compared to children of non-teen mothers, who were more likely to be rated in good/very good/excellent health in one study that did not control for socio-economic status (Wolfe and Perozek 1997). Another study found no differences in self-reported child health (Shaw, Lawlor, and Najman 2006) but did find that children of teen mothers were more likely to report dental fillings at age fourteen as compared to children of older mothers, even after adjusting for family income, maternal education, maternal depression, and family structure. In a Swedish study, Ekéus, Christensson, and Hjern (2004) found that children of teenage mothers had a higher risk of hospital admission for violent as well as 
unintentional injuries, compared to children of older mothers. This risk remained higher even after adjusting for socio-economic variables and indicators of parental substance misuse and psychiatric illness. Jutte et al. (2010) examined health outcomes for children of teen mothers in Manitoba, and found that children of teen mothers were at increased risk of hospitalization; high hospital use; and mortality in infancy, childhood, and adolescence. Adjusting for sex, health at birth (birth weight, small for gestational age, physical condition at birth as measured by the APGAR score), firstborn status, mother's marital status at birth, SES, and number of siblings at age seventeen did not change the results.

A number of studies have also examined the educational outcomes of children of teenage mothers, generally finding that the children of teenage mothers had worse educational outcomes than children of older mothers. Moore, Morrison, and Green (1997) found lower math and reading scores among children of mothers aged seventeen and younger at age of birth, compared to those with mothers aged twenty and twenty-one. These differences remained after controlling for child factors (gender, age, race) and maternal background characteristics (education of highest-educated grandparent, grandmother employment when mother was fourteen, index of reading materials in mother's home at fourteen, mother lived with two biological parents, mother's rural residence at fourteen). Similarly, Turley (2003) found that three- to sixteen-year-old children of younger mothers had worse scores on math, reading, and vocabulary tests compared to children of older mothers. However, when controlling for background characteristics (number of children in the household, presence of spouse, mother's education, and family income) and comparing the children of mothers who began childbearing at an early age with those of their sisters who postponed childbearing, maternal age was only associated with reading scores, and not math or vocabulary scores. Jutte et al. (2010) examined educational outcomes for children of teen mothers (aged less than twenty years old at the birth of their first child) in Manitoba, and found that they were less likely to graduate from high school in comparison to children of mothers whose first child was born at twenty years of age or older. Adjusting for sex, health at birth (birth weight, small for gestational age, physical condition at birth as measured by the APGAR score), firstborn status, mother's marital status at birth, SES, and number of siblings at age seventeen did not change the results.

The studies that have examined social outcomes of children of teenage mothers, mostly in terms of behaviour problems, have found mixed results. Some studies have found higher rates of behaviour problems among children born to teen mothers compared to children born to older mothers (Dahinten and Willms 2002; Moffitt and the E-Risk study team 2002), whereas others did not (Moore, Morrison, and Green 1997). In a nationally representative study of Canadian children, Dahinten and Willms (2002) found that twice as many children of teen mothers had behaviour problems, compared to children of mothers who had delayed childbearing until their mid-twenties. Although reduced after accounting for family background (family income, parent's education, lone parent status), these differences remained significant. Moffitt and the E-Risk study team (2002) found, in Britain, that the five-year-old children of young mothers (who themselves were from fifteen 
to twenty years old) were rated by both parents and teachers as having more emotional and behavioural problems. However, Moffitt and the E-Risk study team (2002) did not adjust for any socio-economic factors. Terry-Humen, Manlove, and Moore (2005) found higher levels of internalizing and externalizing behaviours in kindergarten children of teen mothers compared to children of mothers aged twenty-two to thirty, but also found that the differences were no longer significant when adjusted for family structure, socioeconomic status, and the educational attainment of the child's grandmother. Shaw, Lawlor, and Najman (2006) found that fourteen-year-old children of young mothers (i.e., less than eighteen years at the time of their first birth) had higher rates of behaviour problems (defined as any trouble with police or being suspended from school) compared to children of mothers who were over eighteen years when pregnant. This was true even when adjusted for family income, maternal education, maternal depression, and family structure. Moore, Morrison, and Green (1997) found fewer behaviour problems among four- to fourteenyear-old children of mothers aged nineteen and younger at age of birth, compared to those with mothers aged twenty to twenty-one. The mixed nature of the findings from these studies are possibly due to inconsistent controls for socio-economic factors and different methods of defining and assessing behaviour problems, as well as to differences in samples.

While associations between health, social, and educational outcomes have been examined in children of teen mothers in the overall population, less research has been conducted with First Nations children of teen mothers. Associations between teen motherhood and child health, educational, and social outcomes may differ for First Nations children. While the incidence of teen pregnancy is higher among First Nations compared to the overall Canadian population (Guimond and Robitaille 2008), teenage pregnancy may be perceived differently by First Nations individuals compared to non-First Nations individuals, leading to different outcomes for their children.

The issue of teen parenthood in First Nations communities is culturally complex. In studies focusing on Navajo Native American teen mothers, Dalla and colleagues (Dalla and Gamble 2000; Dalla, Jacobs-Hagen, Jareske, and Sukup 2009) have discussed the importance and value placed on the role of mothers, as well as on children, in Navajo culture, along with how Navajo perceptions of teen pregnancy have been positive and historically normative. However, evidence from both small- and large-scale studies point to difficulties, including socio-economic and educational attainment, for young Aboriginal mothers (Dalla and Gamble 1997; Garner et al. 2013). In a study based on interviews of First Nation and Métis teen mothers in Winnipeg, young mothers identified challenges such as financial hardship, lack of parenting, and life skills, limited access to adequate housing and childcare, and difficulties with transportation. Yet, the women also expressed a strong desire to further their education, find employment, and possibly have more free time for self-care (Murdock 2009). Similar findings have been reported by others. However, in a longitudinal follow-up study of teen mothers, resilience, educational achievements, and employment attainments have also been reported (Dalla, Jacobs-Hagen, Jereske, and Sukup 2009).

Both First Nations and non-First Nations teenaged mothers experience different socio- 
economic circumstances compared to older mothers. Numerous studies have found that teenaged mothers are more likely to be single parents and to have lower levels of income and education (Dahinten and Willms 2002; Moffitt and E-Risk study team 2002; TerryHumen, Manlove, and Moore 2005). In Canada, Dahinten and Willms (2002) found that for the mothers of two- to eleven-year-olds, 51 percent of mothers who were fourteen to seventeen years old at their first birth were single parents, compared to only 12 percent of mothers who were aged twenty-six to thirty years at their first birth. In addition, the mean income of mothers who were fourteen to seventeen years old at their first birth was approximately $\$ 25,000$, compared to $\$ 53,000$ for mothers aged twenty-six to thirty at their first birth.

Garner, Guimond, and Senécal (2013) found that First Nations women who became mothers in their teens had significantly worse socio-economic outcomes when compared to women who postponed motherhood until their twenties. These included lower incomes and a higher likelihood of having poor housing conditions. While First Nations women who became mothers in their teens were less likely to graduate high school than older mothers, teenage mothers who had also graduated high school had better socio-economic outcomes. They had higher personal and household incomes, and were less likely to be living in overcrowded housing or in housing in need of major repair as compared to older First Nations mothers who did not complete high school, suggesting that education, and high school completion in particular, play an important role in the lives of First Nations teen mothers.

This study uses the 2006 Aboriginal Peoples Survey (Statistics Canada 2008) to examine the health, social, and educational outcomes of off-reserve First Nations children aged six to fourteen years old, born to teenage mothers. The first goal is to examine whether or not there are differences in the health, social, and school outcomes of school-aged, off-reserve First Nations children born to mothers who started childbearing in their teens, as compared to school-aged, off-reserve First Nations children born to mothers who started child bearing when they were older. The second goal is to examine the role of socio-economic factors in these associations. Since First Nations teen mothers (and their children) are more likely to live in disadvantaged socio-economic circumstances (Garner, Guimond, and Senécal 2013; Guèvremont and Kohen 2013), which have been found to be important for children's outcomes, it is possible that it is these conditions which contribute to poor outcomes for children, rather than teen childbearing, per se.

The age of the mother when she started having children (regardless of her age when she had the survey child) was used in this study, as opposed to the age of the mother when the survey child was born. We selected "age of mother at first birth" as a category based on the assumption that the factors that led the mother to begin childbearing during adolescence would likely influence not only the child or children born when the mother was a teen but also later born children (Turley 2003). The factors in the mother's life associated with having a child during adolescence may also have longer-term effects on her education and employment, as well as her later family formation and stability (Pogarsky, Thornberry, and 
Lizotte 2006). Furthermore, other research has found that the age of the mother at first birth is more predictive of children's outcomes than the age of the mother at the birth of the target child (Turley 2003).

\section{Methods}

This study is based on data from the child component of the 2006 Aboriginal Peoples Survey (Statistics Canada 2008) covering First Nations children aged six to fourteen not living on reserve. The Aboriginal Peoples Survey was conducted to collect data on the lifestyles and living conditions of Aboriginal peoples in Canada, designed and implemented in partnership with national Aboriginal organizations. Data for First Nations children living on reserve are not available from the APS, thus limiting the generalizability of the results to First Nations children not living on reserve in Canada.

Analyses were conducted on the APS master file. T-tests were conducted for the comparisons of teen and older mothers for socio-economic characteristics as well as the health, social, and school outcomes. To allow for an examination of differences in outcomes between children of teen versus older mothers over and above the impact of socioeconomic conditions, logistic regression models were conducted for each outcome. Models also examined interaction effects by child age and gender with significant results reported in text. Weights were applied to make the data representative of an off-reserve Canadian national sample of First Nations children aged six to fourteen years. Bootstrapped weights were applied to account for the complex survey design via SAS callable Sudaan.

First Nations children were selected based on the question, "Is ___ an Aboriginal person, that is, North American Indian, Métis, or Inuk?" If the parent responded that the child was North American Indian (either North American Indian alone or along with another Aboriginal identity) then they were included in the study. Three out of four mothers $(75 \%)$ of six- to fourteen-year-old off-reserve First Nations children self-identified as Aboriginal themselves (information was not available on whether the mother was First Nations, Métis, or Inuk). ${ }^{2}$

\section{Age of Mother at First Birth}

Similar to our other studies (Guèvremont and Kohen 2013a,b), children were included in the study if the person who responded to the survey was their birth mother. Since the age of the mother at first birth was not collected by the APS, age of first birth was determined by looking at the difference between the mother's current age and the age of the oldest sibling living in the household. If the difference between the mother's age on the day

2 Eighty-three percent of First Nations children not living on reserve with teenage mothers reported having Aboriginal origins compared to $71 \%$ of children with mothers who started childbearing when older than twenty-five. Exploratory analyses were conducted excluding off reserve First Nations children with nonAboriginal mothers yielding similar results (available from author upon request). 
of the survey and the age of the oldest child was less than twenty years, she was classified as a teenage mother. If the difference was greater than or equal to twenty-five years, she was categorized as an "older" mother. If the difference was less than twelve years old, the child was excluded (numbers too small to be reported). Results for children whose mothers were aged twenty to twenty-four when they had their first child were also included in the tables for informational purposes, but are not discussed in the text due to space constraints. ${ }^{3}$

The person who responded to the survey was the birth mother for 64 percent of six- to fourteen-year-old First Nations children not living on reserve. Thus, the sample used for the analyses in this article included 3,971 off-reserve First Nations children aged six to fourteen, weighted to represent a population of 63,280 . In non-included cases, the respondent was the birth father (17\%), a grandparent (5\%), a foster parent (4\%), or another family or non-family member (9\%). These children were not included since maternal age at first birth could not be determined. Off-reserve First Nations children included in the present study (i.e., only children whose birth mothers responded to the survey) were more likely to be living in households with seven or more people ( $9 \%$ vs. $16 \%$ ), more likely to have respondents who had not graduated from high school (23\% vs. $28 \%$ ), less likely to be living in a low income family ( $40 \%$ vs. $32 \%$ ), and more likely to be living in a CA or CMA (72\% vs. 67\%).

\section{Physical Health Outcomes}

Mothers were asked a number of questions about their child's health.

Health status: "In general, would you say his/her health is..." Response categories included excellent, very good, good, fair, and poor. These categories were dichotomized with responses of "excellent" and "very good," compared to "good," "fair," and "poor." Others studies have used this dichotomy for self- or parent-rated health (Tremblay, Dahinten, and Kohen 2003; Garner et al. 2010; Findlay and Janz 2012).

Activity limitation: "Does a physical condition or mental condition or health problem reduce the amount or the kind of activity [child's name] can do: at home; at school; or in other activities, for example, transportation or leisure?" Children were categorized as having an activity limitation if their mother responded they were limited sometimes or often (compared to not limited).

Chronic conditions: "Does [child's name] have any of the following long term conditions that have lasted or are expected to last 6 months or more?" A child was considered as having a chronic condition if their mother reported they had

3 It should be noted that the age of the mother when she started having children does not reflect the current age of the mother at the time of the survey. About half of the children (49\%) whose mothers started having children as teenagers had mothers who were twenty-five years of older at the time of the survey. 
one of a list of health conditions. ${ }^{4}$ Several specific chronic conditions were also examined separately based on prevalence and importance for Aboriginal children (Smylie 2009). These conditions included allergies, asthma, and ear infections or ear problems.

Dental care: "When was the last time [child's name] had any dental care?" Responses were dichotomized, with responses of within the last twelve months compared to more than one year ago. The type of dental care received was also examined, with last dental care being a filling or tooth pulled compared to last dental care being a check-up, cleaning, or orthodontic care. Lastly, mothers were asked, "Does [child's name] need dental treatment at this time?"

Injury: "In the last twelve months, has [child's name] been injured seriously enough to require hospitalization or medical attention by a doctor, nurse, or dentist?"

\section{School Outcomes}

Mothers were also asked a number of questions about their child's schooling.

Child doing very well in school. "Based on your knowledge of [child's name]'s school work, including report cards, overall, how well is [child's name] doing at school this year?" Response categories were dichotomized, with "very well" compared to "well," "average," "poorly," and "very poorly."

Parental importance of post-secondary education. "How important is it to you that [child's name] gets more education after high school?" Response categories were dichotomized, with "very important" compared to "fairly important," "slightly important," and "not important at all."

Grade failure. A proxy for grade failure was developed based on the child's reported grade and age. Grade failure can be impacted by many different factors: for example, boys, children with behaviour problems, and children living in poor socio-economic conditions are more likely to have failed a grade (Beebe-Frankenberger et al. 2004; Frey 2005; Guèvremont, Roos, and Brownell 2007). Although we have statistically controlled for some of these variables in the model (i.e., gender, socio-economic characteristics), we cannot control for other variables which were not included in the survey (e.g., behaviour problems).

4 Conditions included allergies, asthma, bronchitis, tuberculosis, diabetes, heart disease, cerebral palsy, psychological or nervous difficulties, ear infections or ear problems, hearing impairment, visual impairment, mental disability, learning disability, fetal alcohol spectrum disorder, lactose intolerance or trouble digesting milk, attention deficit disorder, autism, arthritis or rheumatism. 
School satisfaction. Parents were considered satisfied with all aspects of the school environment based on responding "agree" or "strongly agree" with ten items about the school (e.g., school's provision of information, level of discipline, quality of teaching; see Appendix for list of all items). The ten items on the scale had high reliability (Cronbach's alpha coefficient $=0.91)$.

\section{Social Outcomes}

Mothers were asked "During the past six months, how well has [child's name] gotten along with: other kids, such as friends or classmates, excluding brothers and sisters; his/ her teachers; his/her parent(s); his/her brothers and sisters?" For each of the above groups, response categories included very well, no problems; quite well, hardly any problems; pretty well, occasional problems; not too well, frequent problems; not well at all, constant problems. For each of the above groups (i.e., other kids, his/her teachers, his/her parent(s), his/her siblings), these categories were dichotomized with responses of "very well" compared to the other groups.

\section{Other Variables}

We examined several child-level characteristics and socio-economic variables to determine their role in explaining differences in outcomes between children of teen mothers and older mothers. Possible explanatory variables included: child age and sex, child's Registered Indian status (as reported by their mothers), mother's education (i.e., currently in school, not in school and not a high school graduate, not in school and a high school graduate), family structure (lone parent or two-parent family), low-income family (family income below low income cut-off), ${ }^{5}$ and number of people living in the household.

Also included as an indicator of living in an urban area was whether the child was living in a census agglomeration (CA) or census metropolitan area (CMA). A CA or CMA is an area consisting of one or more neighbouring municipalities situated around a population centre (known as the core) (Statistics Canada 2009b). A CA must have a population core of at least 10,000 people and a CMA must have a total population of at least 100,000.

\section{Results}

\section{Sample characteristics}

As shown by others previously (Garner, Guimond, and Senécal, 2013; Guèvremont and Kohen, 2013a), off-reserve First Nations children, aged six to fourteen who had teenaged mothers, lived in more difficult socio-economic circumstances when compared to sameaged peers whose mothers were older than twenty-five when they started having children (Table 1).

5 The low-income cut-off (LICO) is a statistical measure of the income thresholds below which families likely devote a larger-than-average share of their income to the necessities of food, shelter, and clothing (Statistics Canada 2009a). 
TABLE 1: Socio-economic characteristics by age of mother at first birth

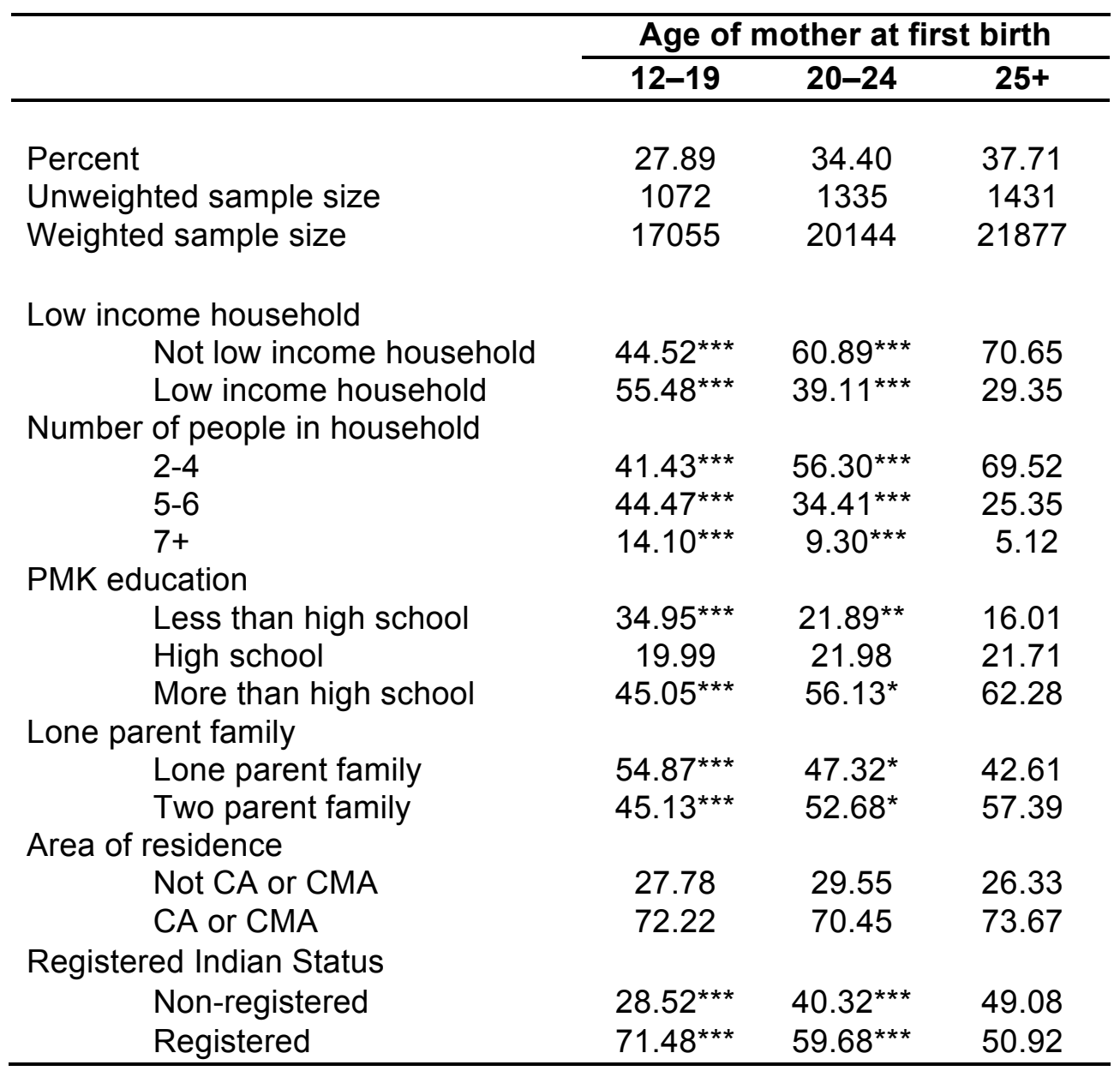

T-test comparisons are to the group with mothers aged 25+

Source: Aboriginal Peoples Survey 2006

${ }^{* * *} \mathrm{p}<0.001,{ }^{* *} \mathrm{p}<0.01,{ }^{*} \mathrm{p}<0.05$

Compared to off-reserve First Nations children of older mothers, off-reserve First Nations children of teen mothers were more likely to be living in low income households (55\% vs. $29 \%$ ), in households of seven or more people (14\% vs. $5 \%$ ), in lone parent families ( $55 \%$ vs. $43 \%$ ), and to have mothers who had not completed high school (35\% vs. 16\%). Off-reserve First Nations children of teen and older mothers were similarly likely to be living in or around an urban area (i.e., living in a CA or CMA). ${ }^{6}$ Off-reserve First Nations children of teenage mothers were more likely to be Registered Indians than off-reserve First Nations children of older mothers (71\% vs. 51\%).

6 Using the definition "living in a CA or CMA" produces the same results as the Statistics Canada definition of urban and rural, where urban is defined as areas with a population of at least 1,000 and a minimum of 400 people per square kilometre (Statistics Canada, 2009b). 
TABLE 2: Outcomes by age of mother at first birth (percentages)

\begin{tabular}{|c|c|c|c|}
\hline & \multicolumn{3}{|c|}{ Age of mother at first birth } \\
\hline & 12-19 & 20-24 & $25+$ \\
\hline \multicolumn{4}{|l|}{ Health Outcomes } \\
\hline In excellent or very good health (vs. good, fair, poor) & 80.19 & 80.33 & 82.39 \\
\hline Activity limitation & 26.74 & 25.81 & 25.04 \\
\hline Health condition (one or more) & $47.79^{* *}$ & 51.45 & 55.53 \\
\hline \multicolumn{4}{|l|}{ Number of health conditions } \\
\hline None & $52.95^{* *}$ & 49.25 & 45.14 \\
\hline One & 25.68 & 24.77 & 27.84 \\
\hline Two & $11.42^{*}$ & 14.91 & 14.97 \\
\hline Three or more & 9.95 & 11.07 & 12.05 \\
\hline \multicolumn{4}{|l|}{ Specific health condition } \\
\hline Allergy & $14.92^{* * *}$ & 20.63 & 23.91 \\
\hline Ear infections or ear problems & 9.21 & 9.26 & 10.02 \\
\hline Asthma & $12.65^{* *}$ & $14.12^{*}$ & 17.85 \\
\hline Child saw doctor in last 12 months & 56.87 & $52.40^{* *}$ & 59.57 \\
\hline \multicolumn{4}{|l|}{ Dental care } \\
\hline Child in need of dental treatment & $35.07^{* *}$ & 31.42 & 28.75 \\
\hline Child received dental care in last 12 months & $78.06^{* * *}$ & $81.85^{*}$ & 85.88 \\
\hline Last dental care was a filling or tooth pulled & $37.94^{* *}$ & 34.71 & 30.21 \\
\hline $\begin{array}{l}\text { Injured in last } 12 \text { months (and required medical } \\
\text { attention) }\end{array}$ & 13.79 & 10.14 & 12.31 \\
\hline \multicolumn{4}{|l|}{ Social outcomes } \\
\hline \multicolumn{4}{|l|}{$\begin{array}{l}\text { Gotten along very well in the last } 6 \text { months } \\
\text { (compared to quite well, pretty well, not well, not well } \\
\text { at all) with: }\end{array}$} \\
\hline Other kids & 60.06 & 62.50 & 64.42 \\
\hline Teachers & $67.84^{*}$ & $68.30^{*}$ & 73.61 \\
\hline Parents & $49.87^{*}$ & 53.87 & 55.12 \\
\hline Siblings & $27.70^{*}$ & 28.78 & 33.05 \\
\hline Other kids, teachers and parents & $33.81^{*}$ & 35.96 & 39.02 \\
\hline \multicolumn{4}{|l|}{ School outcomes } \\
\hline Child doing very well in school & $40.82^{* *}$ & 44.44 & 47.89 \\
\hline $\begin{array}{l}\text { Parent thinks it is important that child gets more } \\
\text { education after high school }\end{array}$ & 87.60 & 89.49 & 90.01 \\
\hline Child is old for grade & $11.29^{* * *}$ & 7.21 & 5.69 \\
\hline $\begin{array}{l}\text { School satisfaction scale-parent satisfied with } 10 \\
10 \text { aspects of school }\end{array}$ & $54.99^{*}$ & $56.43^{*}$ & 61.31 \\
\hline
\end{tabular}

T-test comparisons are to the group with mothers aged 25+

Source: Aboriginal Peoples Survey 2006

${ }^{* * *} \mathrm{p}<0.001,{ }^{* *} \mathrm{p}<0.01,{ }^{*} \mathrm{p}<0.05$ 


\section{Health outcomes}

Off-reserve First Nations children of teen mothers were less likely to have a diagnosed health condition than off-reserve First Nations children of mothers aged twenty-five years old and older when they had their first child (48\% vs. 56\%; Table 2).

TABLE 3: Odds ratios (95\% confidence intervals) predicting health outcomes

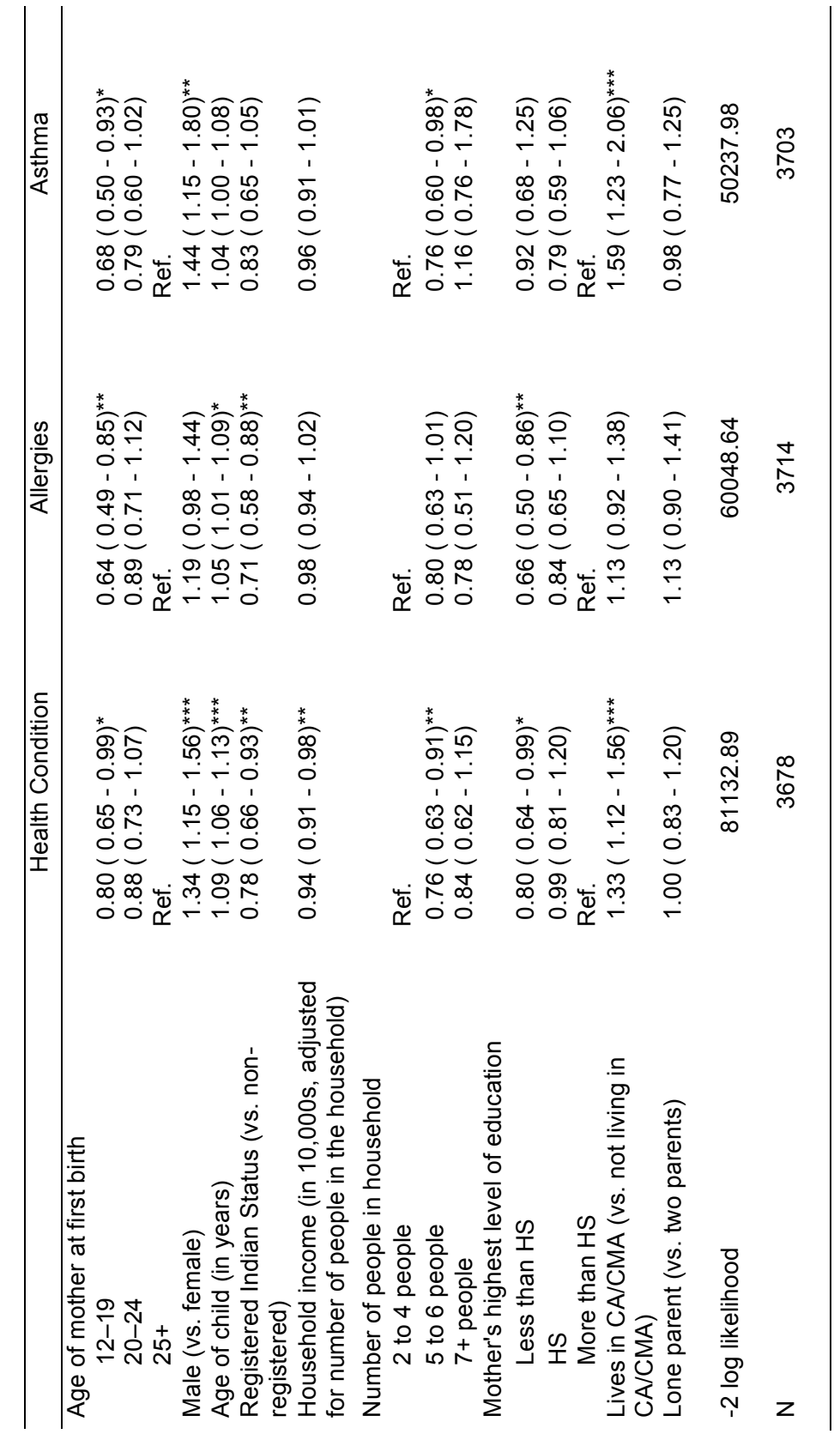

Source: Aboriginal Peoples Survey 2006

${ }^{* * *} \mathrm{p}<0.001,{ }^{* *} \mathrm{p}<0.01,{ }^{*} \mathrm{p}<0.05$ 
Of the specific health conditions asked, First Nations children of teen mothers were less likely to have been diagnosed with allergies (15\% vs. $24 \%)$ or asthma ( $13 \%$ vs. $18 \%)$. These differences remained even when controlling for socio-economic factors (Table 3).

In addition, a significant interaction was found between child and mother's age for diagnosed allergies. For older children, there were bigger differences in reported allergies between teen and older mothers than for younger children.

Off-reserve First Nations children of teen mothers were more likely to have dental issues (Table 2), more likely to need of dental treatment (as reported by their mothers: $35 \%$ vs. 29\%), and less likely to have received dental care in the last twelve months, compared to children of older mothers ( $78 \%$ vs. $86 \%$ ). These differences remained when controlling for socio-economic factors (Table 4).

Although dental care can be preventative in nature, of the children who had received dental care in the last twelve months, children of teen mothers were more likely to have received a filling or to have had a tooth pulled than children of older mothers (38\% vs. 30\%). However, once socio-economic factors were controlled, there were no longer differences between the children of teen and older mothers in having a filling or tooth pulled as the type of last dental care received.

\section{School outcomes}

Off-reserve First Nations children of teen mothers were less likely to be doing very well in school (41\% vs. $48 \%)$ and to have a parent who was satisfied with all aspects of the child's school (55\% vs. 61\%), compared to off-reserve First Nations children of older mothers. In addition, children of teenage mothers were more likely to have failed a grade $(11 \% \mathrm{vs}$. $6 \%)$. After accounting for differences in socio-economic factors between teen and older mothers, there was no longer a significant difference in rates of doing very well in school between off-reserve First Nations children of teen and older mothers. However, differences in parental satisfaction and grade failure remained.

\section{Social outcomes}

Compared to off-reserve First Nations children of older mothers, off-reserve First Nations children of teen mothers were less likely to have gotten along very well in the last six months with their teachers (68\% vs. $74 \%)$, parents (50\% vs. $55 \%)$, and siblings $(28 \%$ vs. 33\%). When socio-economic factors were controlled for, the differences in the rates of getting along very well with teachers and siblings were no longer significant, but differences in rates of getting along very well with parents between children of teen and older parents remained. A significant interaction was found between child gender and how well the child got along with his or her parents. Boys of teen mothers were less likely to get along with their parents than boys of older mothers, but these differences did not emerge for girls. 
TABLE 4: Odds Ratios (95\% confidence limits) predicting dental outcomes

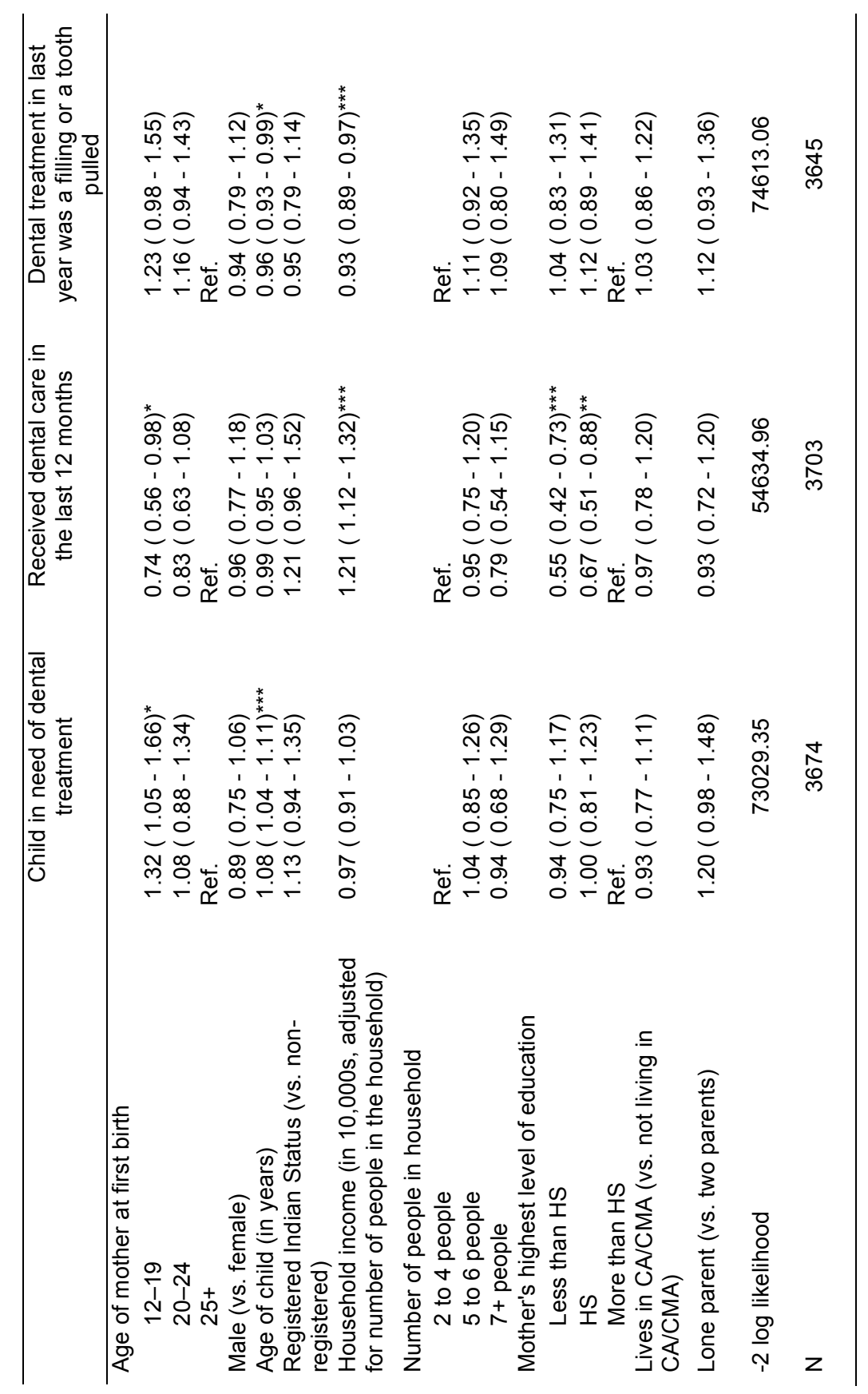

Source: Aboriginal Peoples Survey 2006

${ }^{* * *} \mathrm{p}<0.001,{ }^{* *} \mathrm{p}<0.01,{ }^{*} \mathrm{p}<0.05$ 
TABLE 5: Odds Ratios (95\% confidence limits) predicting school outcomes

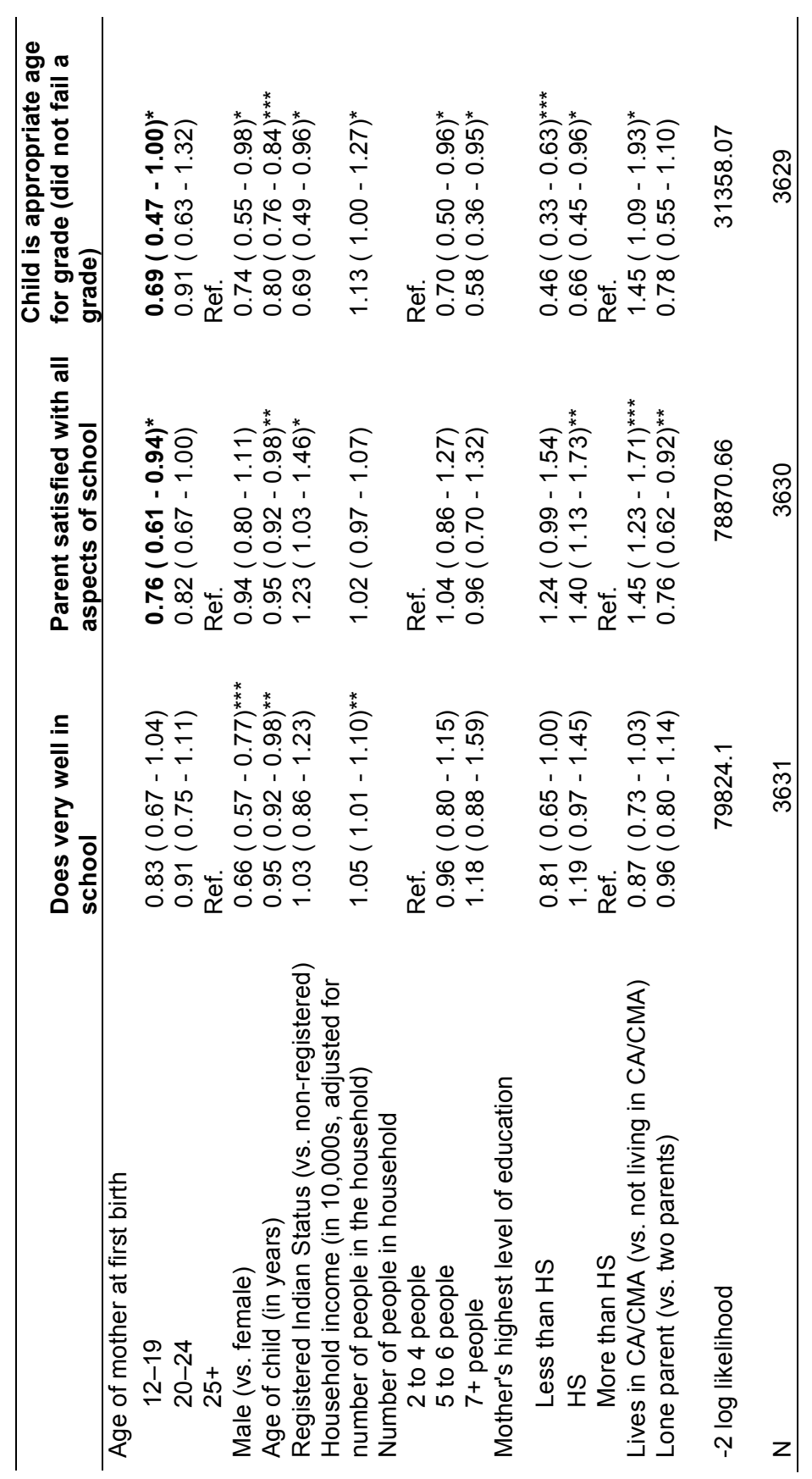

Source: Aboriginal Peoples Survey 2006

${ }^{* * *} \mathrm{p}<0.001,{ }^{* *} \mathrm{p}<0.01,{ }^{*} \mathrm{p}<0.05$ 
TABLE 6: Odds Ratios (95\% confidence limits) predicting social outcomes

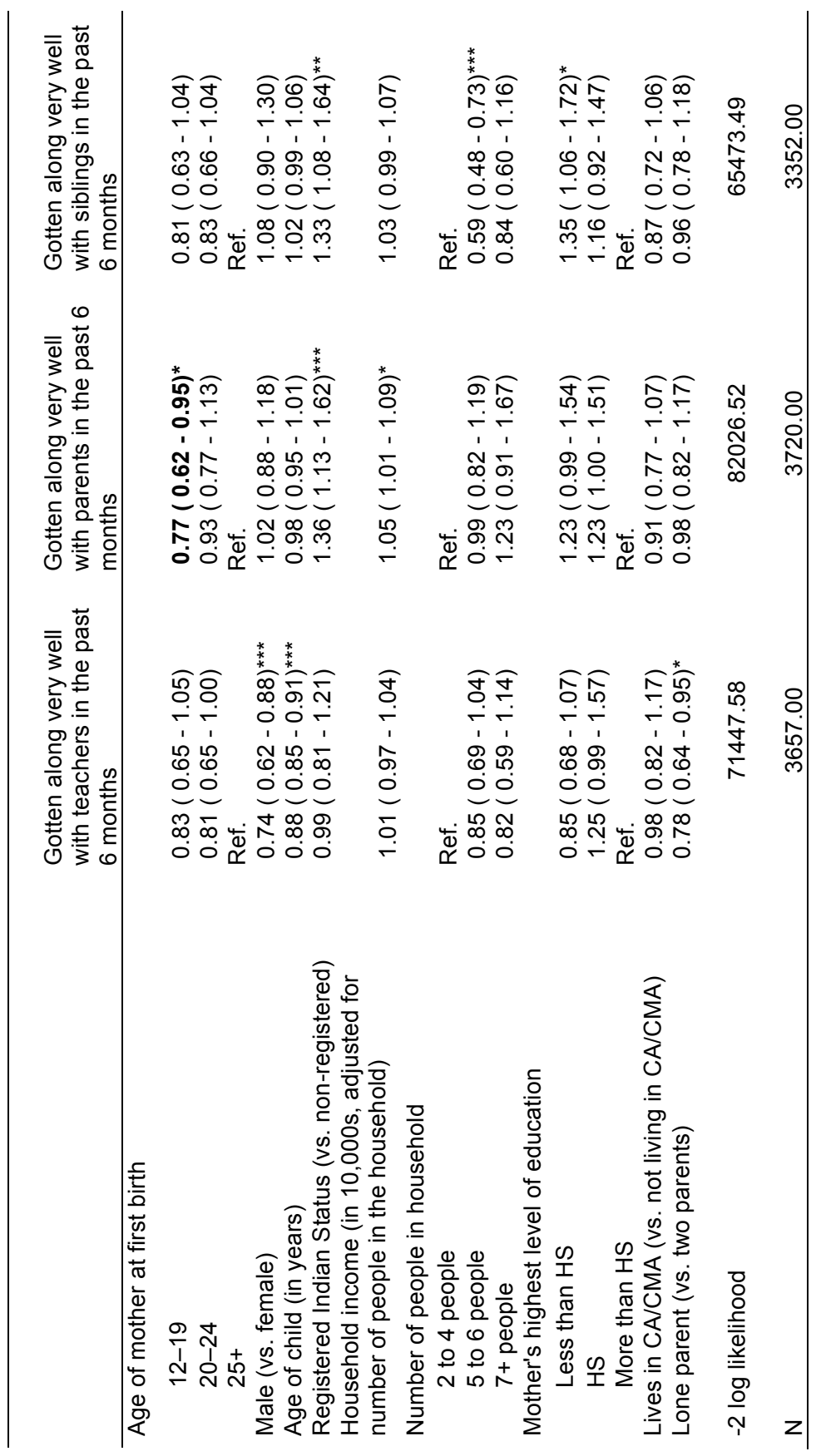

Source: Aboriginal Peoples Survey 2006

${ }^{* * *} \mathrm{p}<0.001,{ }^{* *} \mathrm{p}<0.01,{ }^{*} \mathrm{p}<0.05$ 


\section{Discussion}

Off-reserve First Nations children of teen mothers were more likely to be rated by their mothers as having dental problems, more likely to have failed a grade, less likely to be doing very well in school, and less likely to have mothers who were satisfied with all aspects of the child's school. They were also more likely to be rated as not having gotten along very well in the last six months with their teachers, parents, and siblings. Although some of these differences were explained by socio-economic differences between the children of teen and older mothers, differences in outcomes in each of the three domains remained (dental problems, grade failure and parental school satisfaction, and getting along with parents). In addition, off-reserve First Nations children of teen mothers were less likely to have been diagnosed with an allergy or asthma as compared to off-reserve First Nations children of mothers who were twenty-five years old and older when they started having children; these differences remained when differences in socio-economic factors were accounted for. This finding may suggest better physical health or possibly differences in access, availability, or use of health services: hypotheses that could be examined in future research.

There are several reasons why there might be differences in outcomes between offreserve First Nations children of teen and older mothers. One reason examined in the present study is that children of teen mothers live in different socio-economic conditions than children of older mothers, and that these different conditions impact daily living conditions, daily stress, and interactions between mother and child (McLoyd 1998). We found that off-reserve First Nations children of teenage mothers were more likely to be living in low-income households, to be living in large households, to have mothers with less than a high school education, and to be living in lone parent families as compared to offreserve First Nations children of older mothers. However, even after accounting for these socio-economic factors, differences in outcomes in each of the three domains remained.

Off-reserve First Nations children of teenage mothers were less likely to have been diagnosed with a chronic condition compared to off-reserve First Nations children of older mothers, and decreased rates of allergy or asthma diagnoses in particular. There are several possible reasons for this: off-reserve First Nations children of teen mothers had lower rates of allergy and asthma; off-reserve First Nations children of teen mothers had similar rates of allergy and asthma but were less likely to be diagnosed with allergies or asthma; or offreserve First Nations children of teen mothers had similar rates of allergy and asthma but their mothers were less likely to report that their child was diagnosed with allergies or asthma.

We found that there were no differences in mother-rated child health status or in the percentage of children who had seen a doctor in the last twelve months between offreserve First Nations children of teen mothers and off-reserve First Nations children of older mothers, suggesting that differences were not attributable to poorer overall health or access to care. Other studies have also reported associations between older maternal age and higher rates of allergies (Dioun, Harris, and Hibberd 2003; Metsälä et al. 2010), although several studies have found that older maternal age is associated with decreased 
rates of asthma (Infante-Rivard 1995; Laerum et al. 2007; Lewis et al. 1996). One Canadian study of children in Manitoba found that having a mother who gave birth at an older age was associated with an increased risk of asthma in children under age six (Dik et al. 2004). However, results in a previous study of off-reserve First Nations preschool aged children did not replicate these results (Guèvremont and Kohen, 2013a), with children of teen and older mothers experiencing similar rates of allergies and asthma.

Similar to Guèvremont and Kohen's study of preschool-aged off-reserve First Nations children of teen mothers (Guèvremont and Kohen, 2013a), off-reserve First Nations school-aged children of teen mothers were more likely to have mother-reported dental problems compared to off-reserve First Nations children of older mothers. Although the differences between off-reserve First Nations children of teen mothers and off-reserve First Nations children of older mothers in having received a filling or tooth pulled as their last dental treatment were explained by socio-economic factors, the differences in needing dental treatment and having received dental treatment in the last twelve months were not, with children of teenage mothers more likely to need dental treatment and less likely to have received dental treatment in the last twelve months. Continuous dental problems have been associated with pain and infection, as well as behaviour problems (Health Canada 2009). Registered Indians are eligible to receive services such as dental benefits under the Non-Insured Health Benefits Program (Health Canada 2009); however, Registered Indian status was not associated with dental problems in our study (results available by request).

Differences were also found between off-reserve First Nations children of teen and older mothers in educational and social outcomes. Off-reserve First Nations children of teenage mothers were less likely to be rated as doing very well in school and to have mothers who were satisfied with all aspects of the school, and were more likely to have failed a grade compared to off-reserve First Nations children of older mothers. Differences in doing very well in school were explained by socio-economic differences, whereas parental school satisfaction and grade failure were not. Grade failure is associated with not completing high school as well as future earning potential (Eide and Showalter 2001; Jimerson, Anderson, and Whipple 2002). Off-reserve First Nations children of teen mothers were less likely to have been reported as getting along very well in the last six months with their teachers, parents, and siblings compared to off-reserve First Nations children of older mothers. Differences in getting along with teachers and siblings were explained by socio-economic characteristics, but differences in getting along with parents were not.

This study examined differences in school aged children's health, education, and social outcomes while considering child and family socio-economic factors for off-reserve First Nations children. Differences between children born to teen and older mothers were found in each domain. After considering socio-economic characteristics, dental health, grade failure, and social behaviours such as getting along with parents, remained worse for children of teen mothers compared to children of older mothers. These differences may have lasting impacts: dental problems if unattended to can lead to problems such as increased pain, speech, and behaviour problems (Health Canada 2009). Grade failure can 
limit future education and employment opportunities (Eide and Showalter 2001; Jimerson, Anderson, and Whipple 2002). The differences in diagnosed allergies and asthma warrant further examination by other studies and data sources to better understand the associations between teen parenthood, children's health, and access to care.

Our findings suggest opportunities for prevention for children of teen mothers who may be disproportionately at risk for poor outcomes throughout early, middle, and late childhood. While this study considered important differences between children of teen and older mothers in terms of socio-economic factors, many other factors important both for child outcomes and likely to be associated with teen mothers were not examined and require further investigation. For example, such factors might include parenting behaviours and the availability of social and other supports including father and extended family involvement as well as the influence of knowledge of traditional beliefs and customs (Pogarsky, Thornberry, and Lizotte 2006; Howard et al. 2006; Dalla and Gamble, 1997; Garcia Coll et al. 1986). A dearth of research focusing on fathers is particularly notable and is an area in need of future studies. Replication of these results in both large quantitative and small qualitative studies both on and off reserve would enhance our understanding of these associations as would studies specifically focusing on the processes by which these effects are manifested.

\section{Limitations}

To our knowledge, this is the first large-scale empirical study to look at the health, school, and social outcomes for school-aged off-reserve First Nations children of teenage mothers. Strengths of the study include a population-based sample that was nationally representative of off-reserve First Nations children living in Canada, the examination of outcomes in three domains (health, educational, social), and information on a mother's age when she started having children, as well as the consideration of a variety of socioeconomic characteristics.

Despite these strengths, this study has several limitations. Our measure of maternal age is based on the age of the oldest sibling in the household. It is possible that this sibling was a step, foster, or adoptive sibling, and not a birth sibling. Older children who may have not been living in the home would also be a group that would not have been captured as part of the household. These factors could have lead to inaccuracies in determining the mother's age at first birth. Future studies could include a single item on mothers' age at first childbirth to avoid potential bias. In addition, the outcomes examined in this study were all based on parental reports. Mothers' responses could be influenced by the way they think they should respond, by their experiences, or by the subjective views of their child and differences in outcomes could be due to differences in mothers' perception rather than actual differences. However, Ryan-Krause et al. (2009) compared teenage mothers' assessments of child development with an objective assessment of child development conducted by trained evaluators. They found that the majority (73\%) of mothers accurately assessed their children's development and only 27 percent differed in their assessments. 
Future research could include outcomes from other reporters (i.e., teachers or child care providers) or based on observational measures to gain a better understanding of these differences. Lastly, this study is based on cross-sectional data from one point in time; future research might consider longitudinal studies examining outcomes of off-reserve First Nations children over time.

\section{Conclusion}

Findings from our research using the 2006 Aboriginal Peoples Survey show that there are differences in the health, school, and social outcomes of school age off-reserve First Nations children of teen mothers at their first birth and same age peers of older mothers. Some of these differences (health rating, not doing very well in school, and not getting along very well with teachers and siblings) were explained by socio-economic differences between the off-reserve First Nations children of teenage mothers and the off-reserve First Nations children of older mothers. Other differences (lower rates of allergies and asthma and higher rates of dental problems, not getting along very well with parents, grade failure and lack of parental school satisfaction) remained. Further studies including qualitative and quantitative, as well as longitudinal studies, would help our understanding of the differences in outcomes between the children of teen and older mothers. 


\section{Appendix}

\section{School Satisfaction Items}

How do you feel about the following statements about ___ 's school?

Tell me if you: Strongly agree, Agree, Disagree or Strongly disagree.

This school provided enough information about___s academic process.

This school provided enough information about____s attendance.

This school provided enough information about___s behaviour at school.

I am satisfied with the level of discipline at this school.

I am satisfied with the quality of teaching at this school.

At this school ___ is challenged to work at his/her full potential.

I am satisfied with how this school is preparing ___ to make choices about his/her future.

This school has high academic standards.

I am satisfied with the availability of extracurricular activities at this school.

Overall, ___ is happy at this school. 


\section{Bibliography}

Alexander, K.L., A. Farhat and S.L. Dauber. 1993. "First-Grade Classroom Behavior: Its Short and Long-Term Consequences for School Performance." Child Development 64: 801-14. http://dx.doi.org/10.2307/1131219.

Bai, J., F. Wong and H. Stewart. 1999. "The Obstetric and Neonatal Performance of Teenage Mothers in an Australian Community." Journal of Obstetrics and Gynaecology 19: 345-48.

Beebe-Frankenberger, M., K.M. Bocian, D.L. MacMillan and F.M. Gresham. 2004. "Sorting Second Grade Students: Differentiating Those Retained From Those Promoted." Journal of Educational Psychology 96: 204-15. http://dx.doi.org/10.1037/00220663.96.2.204.

Dahinten, V.S., J. Shapka and J.D. Willms. 2007. "Adolescent Children of Adolescent Mothers: The Impact of Family Functioning on Trajectories of Development." Journal of Youth and Adolescence 36: 195-212. http://dx.doi.org/10.1007/s10964006-9140-8.

Dahinten, V.S. and J.D. Willms. 2002. "The Effects of Adolescent Childbearing on Children's Outcome." In Vulnerable Children: Findings from Canada's National Longitudinal Survey of Children and Youth, ed. J.D. Willms, 243-58. Edmonton: University of Alberta Press.

Dalla, R.L. and W.C. Gamble. 1997. "Exploring Factors Related to Parenting Competence among Navajo Teenage Mothers: Dual Techniques of Inquiry." Family Relations 46 (2): 113-21. http://dx.doi.org/10.2307/585035.

. 2000. "Mother, Daughter, Teenager-Who Am I?" Journal of Family Issues 21(2): 225-45.

Dalla, R.L., S.B. Jacobs-Hagen, B.K. Jareske and J.L. Sukup. 2009. "Examining the Lives of Navajo Native American Teenage Mothers in Context: A 12- To 15-Year Follow-Up." Family Relations 58: 148-61. http://dx.doi.org/10.1111/j.17413729.2008.00543.x.

Dik, N., R.B. Tate, J. Manfreda and N.R. Anthonisen. 2004. "Risk of Physician-Diagnosed Asthma in the First 6 Years of Life." Chest 126: 1147-53. http://dx.doi.org/10.1378/ chest.126.4.1147.

Eide, E.R. and M.H. Showalter. 2001. "The Effect of Grade Retention on Educational and Labor Market Outcomes." Economics and Education Review 20: 563-76. http:// dx.doi.org/10.1016/S0272-7757(00)00041-8.

Ekéus, C., K. Christensson and A. Hjern. 2004. "Unintentional and Violent Injuries among Pre-School Children of Teenage Mothers in Sweden: A National Cohort Study." Journal of Epidemiology Community Health 58: 680-85.

Findlay, L. and T. Janz. 2012. "Health of First Nations Children Living Off Reserve and Métis Children Younger Than Age 6." Health Reports 23 (1): 1-9.

Frey, N. 2005. "Retention, Social Promotion, and Academic Redshirting: What Do We Know and Need to Know?" Remedial and Special Education 26: 332-46. http:// dx.doi.org/10.1177/07419325050260060401. 
Garcia Coll, C., B.R. Vohr, J. Hoffman and W. Oh. 1986. "Maternal And Environmental Factors Affecting Developmental Outcomes of Infants of Adolescent Mothers." Developmental and Behavioral Pediatrics 7: 230-36.

Garner, R., G. Carrière, C. Sanmartin and the Longitudinal Health and Administrative Data Research Team. 2010. The Health of First Nations Living Off-Reserve, Inuit, and Métis Adults in Canada: The Impact of Socio-economic Status on Inequalities in Health. Ottawa, ON: Statistics Canada.

Garner, R., E. Guimond and S. Senécal. 2013.'The Socio-Economic Characteristics of First Nations Teenage Mothers." Special issue on Indigenous Early Parenthood. International Indigenous Policy Journal, 4 (1): 1-25.

Geronimus, A.T. 2003. "Damned If You Do: Culture, Identity, Privilege, and Teenage Childbearing in the United States." Social Science and Medicine 57: 881-93. http:// dx.doi.org/10.1016/S0277-9536(02)00456-2.

Guèvremont, A. and D. Kohen. 2013a. "The Physical and Mental Health of First Nations Children Not Living on Reserve with Teen Mothers." Special issue on Indigenous Early Parenthood. International Indigenous Policy Journal 4 (1): 1-29.: http:// ir.lib.uwo. ca/iipj/vol4/iss1/2.

- 2013b. "Do factors other than SES explain differences in child outcomes between teenage and older mothers for off-reserve First Nations children?" International Indigenous Policy Journal 4 (3): 1-26. http://ir.lib.uwo.ca/iipj/vol4/iss3/6

Guèvremont, A., N.P. Roos, and M.D. Brownell. 2007. "Predictors and Consequences of Grade Retention: Examining Data from Manitoba, Canada." Canadian Journal of School Psychology 22 (1): 50-67.

Guimond, E. and N. Robitaille. 2008. "When Teenage Girls Have Children: Trends and Consequences." Horizons 10 (1): 49-51.

Health Canada. 2009. "Non-Insured Health Benefits for First Nations and Inuit." Ottawa, ON: Health Canada. Retrieved January 17, 2013 from: http://www.hc-sc.gc.ca/ fniah-spnia/nihb-ssna/index-eng.php.

Health Canada. 2009. “The Effects of Oral Health on Overall Health." Ottawa, ON: Health Canada. Retrieved January 17, 2013 from: http://www.hc-sc.gc.ca/hl-vs/iyh-vsv/ life-vie/dent-eng.php.

Howard, K., J. Lefever, J. Borkowski, and T. Whitman. 2006. "Father's Influence in the Lives of Children With Adolescent Mothers." Journal of Family Psychology 20: 468-76.

Infante-Rivard, C. 1995. "Young Maternal Age: A Risk Factor for Childhood Asthma?" Epidemiology 6: 178-80. http://dx.doi.org/10.1097/00001648-199503000-00016.

Jimerson, S.R., G.E. Anderson, and A.D. Whipple. 2002. "Winning the Battle and Losing the War: Examining the Relation between Grade Retention and Dropping Out of High School." Psychology in the Schools 39: 441-57. http://dx.doi.org/10.1002/pits.10046.

Jutte, D.P., N.R. Roos, M.D. Brownell, G. Briggs, L. MacWilliam, and L.L. Roos. 2010. “The Ripples of Adolescent Motherhood: Social, Educational, and Medical Outcomes for Children of Teen and Prior Teen Mothers." Academic Pediatrics 10: 293-301. http:// dx.doi.org/10.1016/j.acap.2010.06.008. 
Lewis, S., B. Butland, D. Strachan, J. Bynner, D. Richards, N. Butler, and J. Britton. 1996. "Study of The Aetiology of Wheezing Illness at Age 16 in Two National British Birth Cohorts." Thorax 51: 670-76. http://dx.doi.org/10.1136/thx.51.7.670.

Lavigne, J.V., C. Cicchetti, R.D. Gibbons, H.J. Binns, L. Larsen, and C. DeVito. 2001. "Oppositional Defiant Disorder with Onset in Preschool Years: Longitudinal Stability and Pathways to Other Disorders." Journal of the American Academy of Child and Adolescent Psychiatry 50 (12): 1393-400. http://dx.doi.org/10.1097/00004583200112000-00009.

McClelland, M.M., F.J. Morrison, and D.L. Holmes. 2010. "Children at Risk for Early Academic Problems: The Role of Learning Related Social Skills." Early Childhood Research Quarterly 15: 307-29. http://dx.doi.org/10.1016/S0885-2006(00)00069-7.

McLoyd, V. 1998. "Socioeconomic Disadvantage and Child Development." American Psychologist 53 (2): 185-204. http://dx.doi.org/10.1037//0003-066X.53.2.185.

Millar, W.J., and J. Chen. 1998. "Maternal Education and Risk Factors for Small-ForGestational Age Births." Health Reports 10 (2): 43-51.

Moffitt, T. and the E-Risk Study Team. 2002. "Teen-aged Mothers in Contemporary Britain." Journal of Child Psychology and Psychiatry 43 (6): 727-42. http://dx.doi. org/10.1111/1469-7610.00082.

Moore, K., D. Morrison, and A. Green. 1997. "The Effects on the Children Born to Adolescent Mothers." In Kids Having Kids, ed. R Maynard, 145-80. Washington, DC: The Urban Institute Press.

Murdock, L. 2009. Young Aboriginal Mothers in Winnipeg. Winnipeg, MB: The Prairie Women's Health Centre of Excellence. http://www.pwhce.ca/pdf/ YoungAboriginalMothersInWinnipeg.pdf

Pittard, W., J. Laditka, and S. Laditka. 2008. "Associations between Maternal Age and Infant Health Outcomes: Among Medicaid-Insured Infants in South Carolina: Mediating Effects of Socioeconomic Factors." Pediatrics 122: e100-e106. http://dx.doi. org/10.1542/peds.2007-1314.

Pogarsky, G., T. Thornberry, and A. Lizotte. 2006. "Developmental Outcomes for Children of Young Mothers." Journal of Family Psychology 68: 332-44. http://dx.doi. org/10.1111/j.1741-3737.2006.00256.x.

Ryan-Krause, P., M. Meadows-Oliver, L. Sadler, and M.K. Swartz. 2009. "Developmental Status of Children of Teen Mothers: Contrasting Objective Assessments with Maternal Reports." Journal of Pediatric Health Care 23: 303-309. http://dx.doi. org/10.1016/j.pedhc.2008.09.001.

Shaw, M., D. Lawlor, and J. Najman. 2006. “Teenage Children of Teenage Mothers: Psychological, Behavioural and Health Outcomes from an Australian Prospective Longitudinal Study." Social Science and Medicine 62: 2526-39. http://dx.doi. org/10.1016/j.socscimed.2005.10.007.

Smylie, J. 2009. Indigeneous Children's Health Report: Health Assessment in Action, ed. J. Smiley and P. Adomako. Toronto, ON: Keenan Research Centre. 
Statistics Canada. 2008. "Aboriginal Peoples Survey 2006: Concepts and Methods Guide." Ottawa, ON: Minister of Industry.

- - . 2009a. "Low Income Cut-Offs for 2008 and Low Income Measures for 2007." Ottawa, ON: Minister of Industry.

- - _. 2009b. "Census Geography." Retrieved January 15, 2013 from: http://www12. statcan.gc.ca/census-recensement/2006/ref/dict/overview-apercu/pop6-eng.cfm.

Terry-Humen, E., J. Manlove, and K. Moore. 2005. "Playing Catch-Up: How Children Born To Teen Mothers Fare.” Washington, DC: National Campaign to Prevent Teen Pregnancy.

Tjepkema, M. and R. Wilkins. 2011. "Remaining Life Expectancy At Age 25 And Probability Of Survival To Age 75, By Socioeconomic Status And Aboriginal Ancestry." Health Reports 22 (4): 1-6.

Tremblay, S., V.S. Dahinten, and D. Kohen. 2003. "Factors Related to Adolescents' SelfPerceived Health.” Health Reports 14: 7-16.

Turley, R.N.L. 2003. "Are Children of Young Mothers Disadvantaged because of Their Mother's Age or Family Background?" Child Development 74 (2): 465-74.

Wolfe, B. and M. Perozek. 1997. "Teen Children's Health and Health Care Use." In Kids Having Kids, ed. R Maynard, 181-203. Washington, DC: The Urban Institute Press.

Zukewich, N. and V. O'Donnell. 2008. Aboriginal Children's Survey, 2006: Family, Community and Child Care. Ottawa, ON: Minister of Industry. 